\title{
Local Income Inequality
}

\author{
Rubén Hernández-Murillo
}

A lthough national income inequality is a subject of great concern in the popular press and in political rhetoric, income inequality at the local level is more evident because inequality tends to be much higher in densely populated areas; consequently, some economists focus their attention there. The chart shows a correlation of 45 percent between county-level income inequality and population density for 2007. Differences in local inequality reflect, for the most part, three important factors: differences in the distribution of job skills, differences in the returns that individuals gain from their skills, and differences in government policies.

Economists Glaeser, Resseger, and Tobio find that almost one half of the variation in income inequality across metropolitan areas can be explained by differences in the distribution of skills. ${ }^{1}$ They identify two reasons for this: First, particularly at the medium and high skill levels, the differences in skills observed today can be explained largely by the historical patterns from several decades ago; in other words, historical patterns of skill level are very persistent. Second, where people choose to live, especially those with lower skill levels, affects the distribution of skills: For example, recent Hispanic immigrants have disproportionately lower skill levels than immigrants from other ethnic backgrounds and lower skill levels than immigrants from previous decades. Historical patterns are also important in this case because many Hispanic immigrants often locate in the same areas of the country-those geographically close to Latin America, such as California, Texas, and Florida.

Inequality across cities also reflects differences in the returns to skill, although it is not clear why skill is rewarded more in some places than others. One potential explanation is that densely populated areas generate human capital spillovers (i.e., the sharing or passing on of skills) because of the concentration of skilled individuals working together, which causes the returns to rise. Economists also recognize that highly skilled individuals are sensitive to differences in these returns and can easily migrate to those places where their skills are valued more.

Differences in government policies also explain some of the variation in income inequality. However, the high mobility of more skilled, and consequently richer, individuals severely limits the ability of local governments to reduce inequality by redistributing wealth: As noted, the richer and highly skilled will move if returns to skill decline. Communities with more generous redistributive policies, in the form of welfare programs, also affect the location patterns of less skilled immigrants and will tend to attract more poor individuals.

Glaeser, Resseger, and Tobio suggest that education policies to improve the skill levels of individuals at the bottom of the distribution might be more effective at reducing inequality than redistributive policies. They warn, however, that changing the distribution of human capital would take several years, if not decades. More important, they note that because the United States has a decentralized schooling system, in which schools are run by local governments, attempts to equalize education opportunities across cities would require potentially difficult and costly coordination between national and local governments.

\footnotetext{
${ }^{1}$ Glaeser, Edward L.; Resseger, Matthew G. and Tobio, Kristina. "Urban Inequality." NBER Working Paper No. 14419, National Bureau of Economic Research, October 2008; http://papers.nber.org/papers/w14419.
}

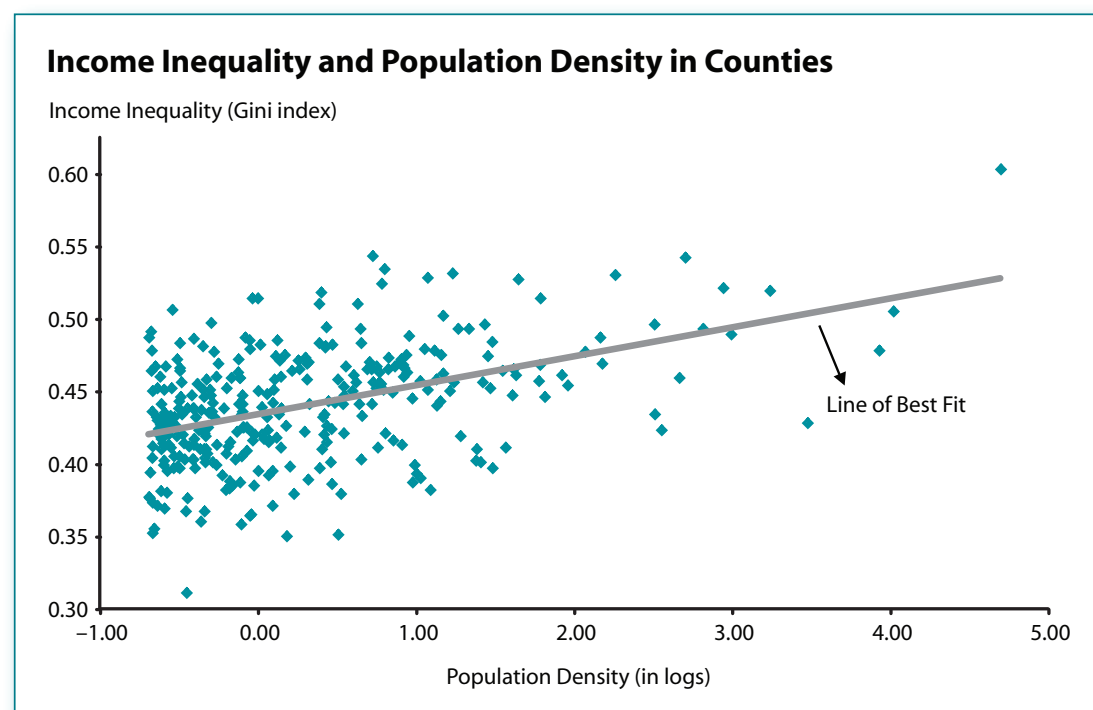

NOTE:The Gini index ranges between 0 and 1 and indicates how unequal a distribution is relative to a distribution that is perfectly even. A larger index value indicates higher inequality. Population density is measured as the number of persons per acre and only counties with a population density of more than one person for every two acres are included in the plot.

SOURCE: U.S. Census Bureau, 2007 American Community Survey. County acreage measures are from the 2000 Census. 